\title{
Applications of Financial Technology in Foreign Exchange Market
}

\author{
Wei $\mathrm{Li}^{1, \mathrm{a}}$ \\ ${ }^{1}$ Nankai University, 94 Weijin Road, Nankai District, Tianjin, China
}

\begin{abstract}
Financial technology (Fintech), including a series of advanced technologies such as big data, artificial intelligence and block-chain, has been gradually applied to various industries after years of development and will become the major driver of the future financial industry. As one of the largest financial markets in the world, the traditional foreign exchange service industry is gradually entering the era of fintech, bringing new vitality to the foreign exchange market through advanced technology and improving the efficiency of foreign exchange management. However, while enjoying the opportunities brought by fintech to the foreign exchange field, practitioners in both fintech and the foreign exchange industry should also actively face the challenges and try to build a safe and efficient foreign exchange market environment.
\end{abstract}

\section{INTRODUCTION}

Fintech, as the name implies, refers to the mutual penetration and integration of finance and technology, driving the innovation of financial industry with advanced technology. According to the definition of the Financial Stability Board (FSB), fintech mainly refers to emerging business models, new technology applications, new products and services that are driven by new cutting-edge technologies such as big data, block-chain, cloud computing and artificial intelligence and have a significant impact on the financial market and the supply of financial services.

The foreign exchange market is one of the world's biggest financial markets. Thus, with the rapid development of the Internet and investors' growing preference for investing in the field of foreign exchange, it is inevitable for the traditional foreign exchange service industry to enter the era of fintech. Therefore, how to best integrate the foreign exchange industry and fintech and how to apply them have become a question that people are willing to think about.

This paper will discuss certain features of the foreign exchange market to explore the applications of fintech in the field of foreign exchange. Furthermore, by digging through the existing problems in the foreign exchange market, in combination with the meanings and characteristics of a series of technological innovations such as big data, block-chain and artificial intelligence, we will also investigate which new business models, applications or products these technologies can create for the foreign exchange industry, so as to promote the upgrading of the structure of the foreign exchange market and the improvement of trading efficiency.

\section{APPLICATION OF FINTECH IN FOREIGN EXCHANGE MARKET}

As asset allocation is becoming more international and more countries are opening up their financial markets, investors increasingly favor investments which include foreign exchange exposure. At the same time, investors put forward higher requirements on trading systems, products and services, and their diversified and personalized demands symbolize their pursuit of efficiency and experience. A series of technological innovations brought by fintech can well solve some problems in the foreign exchange market and meet the needs of customers and markets.

Looking at the direction of fintech innovation at the current stage, we generally believe that big data, artificial intelligence and block-chain are the three core technology bases for current and future fintech development. The three technologies are not mutually iterative and time-axis related, but complement each other and promote each other, supporting the development of fintech in different levels and aspects at the same time.

\subsection{The Big Data}

As a hot industry in recent years, the value of big data lies not only in the "large" amount of data that can be acquired and stored, but also in its ability to have value extracted from large-capacity data through analysis. In the foreign exchange market, common foreign exchange data such as balance of payments, current account, capital account, comprehensive management and other 
business lines, including cross-border income and expenditure, trade credit and dozens of specific projects, can be timely and effectively integrated through big data analysis. With the help of the analysis offered by the big data, government officials will have a better understanding of the balance of payments situation and take precautions against the impact of some unexpected risks in advance, thereby promoting the basic balance of cross-border capital flows and the overall stability of the national economy.

Furthermore, big data analysis emphasizes the correlation between variables rather than the traditional causality and focuses on finding variables that are highly correlated with the research object through technical means [1]. In foreign exchange management, if we can pay more attention to the changes of relevant variables, we can be more sensitive to the factors affecting the operation of the foreign exchange market, such as the changes in interest rates and exchange rates for different currency, thus effectively monitoring the foreign exchange situation.

\subsection{Artificial Intelligence}

Compared with big data, the core breakthrough of artificial intelligence lies in deep learning, intelligent analysis and ultimately intelligent decision-making. In order to scientifically and rationally apply artificial intelligence in the field of foreign exchange, we can use the deep learning technology. By importing a large number of historical foreign exchange data, such as the massive amounts of import and export, cross-border payments and written guarantee, combined with domestic and international economic and financial situation, we can analyze the scale, the trend and the spreads, judge the direction of the cross-border capital flow, make sure cash flow status and predict possible risk of cross-border capital flows, thus changing the ex-post supervision of foreign economy into pre-risk warning and in-process monitoring, providing a basis for formulating foreign exchange management policies and measures [2].

In addition to analysis in the macro field, artificial intelligence can also effectively help investors effectively avoid risks in the foreign exchange options or futures market. For example, by deeply learning historical data and information of foreign exchange, such as the international balance of payments, inflation and interest rates changes, the implementation of the exchange rate policy and so on, we can predict the future of the currency exchange rate trends. Then, the application of artificial intelligence in foreign exchange field will be elaborated through examples of "Robo-advisor" and "Regulatory Sandbox".

\subsubsection{Robo-advisor}

Robo-advisor, also known as robot investment advisor or automatic financial management, originated in the United States. Robo-advisor is the combination of artificial intelligence and big data, which aims to make comprehensive use of big data technology for calculation and selection of optimal schemes, understand market operation rules and users' personalized risk preferences, etc. Therefore, fundamentally speaking, the coverage of data also directly affects the results of robo-advisor [3].

In the field of foreign exchange, there are still problems of low service efficiency, such as the difficulty of getting timely and satisfactory answers for customers, the strong specialty required to enter the foreign exchange market and high threshold of the market. Thus, these problems are exactly the direction and opportunity of foreign exchange industry reform.

For these reasons, robo-advisor can bring a series of humanized services to the foreign exchange market. Through the accumulation of data and machine information in daily services, the machine can imitate human behaviors and ways to provide basic services to customers, such as the popularization of online intelligent customer service system. Aiming at all kinds of products in foreign exchange business and the needs and risk appetite of different customers, robo-advisor, for one thing, can investigate the satisfaction of products and deficiencies, for another, analyze the behaviors and habits of customers. Therefore, it can provide the direction for the update and optimization of the company's products as well as a better investment portfolio for customers.

However, in the current foreign exchange market, in any case, robo-advisor cannot completely replace actual consultant. On the one hand, it is due to the technology of capability that needs to be further improved; on the other hand, there are also credit and regulatory issues. For example, some platforms sell products under the banner of "intelligent investment", but actually, they do not have the analysis ability of the financial products. Therefore, robo-advisor and consultant must be complementary to each other.

\subsubsection{Regulatory Sandbox}

Regulatory sandbox, one of the applications of artificial intelligence in Financial regulation, is one of the typical innovative regulatory models in developed countries or regions. It was first proposed by the UK Financial Conduct Authority (FCA). 


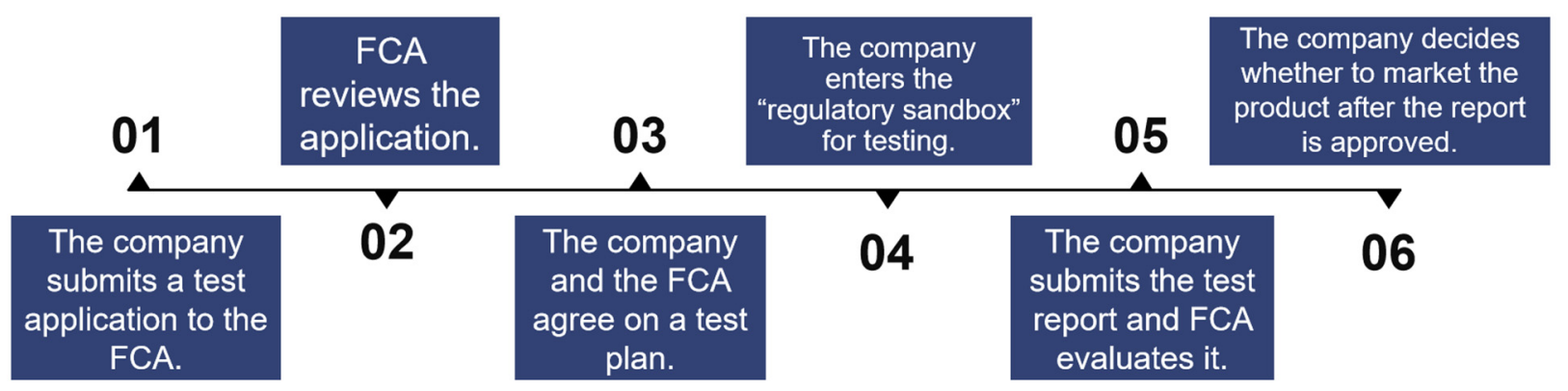

Figure 1. The FCA "Regulatory Sandbox" Process [3].

In the current international foreign exchange situation, where exchange rate changes rapidly, financial institutions often launch new foreign exchange credit and financing products to attract customers, and thus, one of the problems in foreign exchange management is that foreign exchange regulatory mode often fails to catch up with the innovation speed of financial products. For financial products with unknown financial risks, we can rely on artificial intelligence technology and take advantage of the sandbox to establish a testing environment of foreign exchange supervision sandbox, which can quickly and effectively evaluate the value and risk of innovative financial products and financial services. Then it will determine whether these new products can be successfully promoted and listed. In this way, the sandbox test of foreign exchange supervision reduces the supervision cost of financial innovative products and services, which not only encourages the financial innovation of financial institutions, but also achieves the purpose of effectively preventing risks, which can be said to kill many birds with one stone [4].

\subsection{Block-chain}

Block refers to the packaging of system transaction information into an information block or accounting block over a period of time to verify and store data; block-chain, guaranteed by cryptography, is a kind of chain data structure combining data blocks in order of time sequence, and a non-tamper and non-forgery distributed open ledger technology. As one of the most challenging innovations in fintech, block-chain has become the mainstream technology system after years of development.

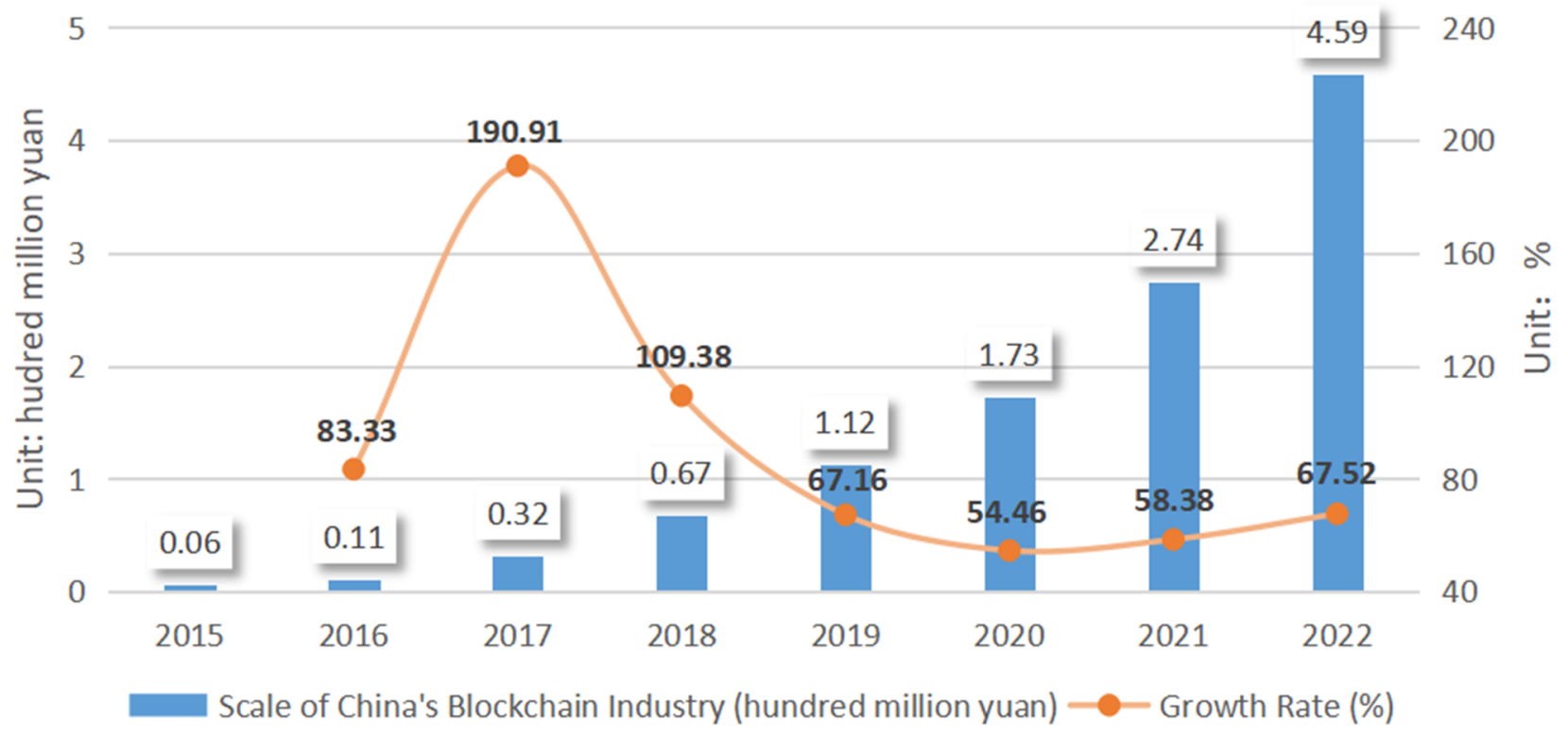

Figure 2. Market Size of China's Block-chain Industry and its Growth Forecast from 2005 to 2020 (Data source: Forward Industry Research Institute)

With the continuous decentralization of foreign exchange business authority, safe offices can only use technical means from the background to achieve full caliber analysis and monitoring of cross-border funds, and the data monitored and analyzed by safe are basically from the handling Banks, which means that the safe offices cannot directly understand trading purpose or get the absolutely real trade data. And these problems result in information asymmetry, such as uncertainty about the business intention of internal security and external loan of enterprises, coupled with difficulty in grasping the authenticity of some special foreign exchange documents, which makes it harder to supervise in foreign exchange market[5]. 
However, block-chain technology can build a trusted trading environment by virtue of its technical characteristics of distributed bookkeeping and point-to-point transmission, effectively alleviating information asymmetry. Block-chain, based on consensus mechanism and cryptographic algorithm, makes the recorded data become the consistent information of the whole network through information broadcast, timestamp, transaction signature and other means, which is hard to change and irreversible [6]. Therefore, when enterprises conduct cross-border transactions or banks handle foreign exchange business, an open and credible trading environment can be formed through the block chain, and all trading processes will be recorded and made public, maximizing the opportunity cost of information fraud.

The application of block-chain in the financial field also includes supply chain finance, asset digitalization, transaction clearing and settlement, etc. Take cross-border payments as an example. Currently, SWIFT, the global system for handling inter-bank international settlement, mainly provides financial information transmission service and transaction processing service. Block-chain, however, by virtue of its point-to-point transmission, distributed data storage and extremely low transaction costs, can also provide a series of financial activities, including domestic and overseas payment, asset management and transaction, reduce inter-bank settlement fees and costs, and improve efficiency [7].

\section{CHANLLENGES POSED BY FINTECH}

The development of fintech has injected new blood into the foreign exchange field and provided strong technical support. However, while fintech has brought unprecedented new opportunities to the foreign exchange market, it has also increased the risks and uncertainties of the foreign exchange business, bringing some new challenges to foreign exchange management.

\subsection{Technical Risk}

One of the preconditions for the widespread use of fintech is that a large amount of basic data has been input and applied through various algorithms. However, the technology itself cannot determine whether the basic data is correct or not. Once the wrong data is used, it will bring greater risks.

\subsection{Network Risk}

Speculators use the financial network to conduct a large number of related transactions in the stock market, the foreign exchange market and the futures market, resulting in the ups and downs of the financial market. For example, the online exchange speculation refers to the illegal foreign exchange margin trading with the help of the international Internet. Under the banner of "foreign exchange trading", criminals often take advantage of the public's insufficient understanding of the foreign exchange trading and their curiosity to set up a fake platform for fraud and profit, seriously disrupting the financial order.

\subsection{Credit Security Risk}

Market activities presented by digitalization, virtualization, cloud services and other means may obscure participants' identity characteristics and behavior patterns, and some technical loopholes may lead to illegal access to investment data, invasion of investors' privacy, and even the disclosure of sensitive data, endangering the national financial security[8].

\subsection{Business Risk}

As fintech makes the structure of financial businesses more complex, speeds up trading and massively increases volumes, its risks become more diffuse and disruptive. When system defects, technical failures or other accidents happen, it may cause local market fluctuations or even systemic risks.

\section{CONCLUSION}

In general, from the perspective of the current development trend, fintech is allowing innovations developed in the financial industry. With the in-depth development of big data, artificial intelligence and block chain, these innovative technologies will also be more widely and rigorously applied to foreign exchange market transactions and foreign exchange management.

This paper also briefly analyzes the financial technology applied in the process of the possible risks, so in the future of financial regulation, practitioners in the fintech industry and relevant regulators should work together to build a long-term, orderly and safe sound mechanism and ecosystem for the fintech industry. For example, governments should actively adopt both legal supervision and technological supervision-in terms of technology, it is recommendable to improve relevant technology of financial supervision, and use intelligent analysis technology to realize dynamic supervision of fintech industry; In terms of law, on the basis of establishing a unified application platform for financial regulation, officials should strengthen administrative legislation, improve relevant laws and intensify punishment to effectively prevent and control financial risks.

\section{ACKNOWLEDGEMENT}

I would like to show my gratitude to my teachers, who has reviewed the paper and helped me by sourcing the data.

\section{References}

1. D. X.Wang. The "Eye-opening" Effect of Big Data Analysis in the Application of Foreign Exchange Management [J]. Financial Economics, 2019(15):45-46. 
2. Z. Zhang. The Application Exploration of Regulatory Technology in Foreign Exchange Management [J]. Science and Technology and Finance, 2019(11):64-66.

3. H. J. Zhai. Research on the Development of China's Intelligent Investment Market under the Background of Fintech [J]. China High-tech, 2018(19):51-52.

4. Z. G. Wang, Y. N. Li, W. T. Yu and W. Zhao. Exploration of artificial Intelligence in Promoting Foreign Exchange Management of Current Account [J]. Jilin Finance Research, 2018(11):37-41.

5. H. B. Bi. Application Exploration of Blockchain in Foreign Exchange Work [J]. Information Technology and Informatization, 2019(12):194-196.

6. T. Wu and M. Li. New Dimension of Blockchain Financial Regulation and Governance [J]. Financial Science, 2019(11):1-11.

7. J. F. Ke. Practice and Thinking of Blockchain in Finance $[\mathrm{J} / \mathrm{OL}]$. Journal of Guangxi Normal University (Philosophy and Social Sciences Edition): 1-11 [2020-02-22].

8. X. D. Ma. New Challenges Brought by Fintech Development [N]. China Insurance News, 2019-03-05(005). 